\title{
ESTUDIO DE CONSTITUCIONALIDAD DEL PARÁGRAFO DEL ARTÍCULO 57 DE LA LEY 1453 DE 2011
}

\author{
Illiana Andrea Sánchez Gil² \\ Javier Alberto Alcárcel Cepeda ${ }^{3}$
}

Fecha de recepción: 22 de noviembre de 2016

Fecha de aceptación: 13 de diciembre de 2016

SUMARIO: 1. Introducción; 2. Prolegómeno; 3. Principio de legalidad; 4. Debido proceso; 5. Derecho a la igualdad; 6. Sobre el Sistema Penal Acusatorio; 7. Sobre la declaratoria de exequibilidad del parágrafo del articulo 57 de la Ley 1453 de 2011; 8. Conclusiones; 9. Referencias bibliográficas.

1 Articulo cientifico presentado como trabajo de grado para optar al titulo de Especialista en Procesal Constitucional y Derecho Penal Militar. Universidad Militar Nueva Granada.

2 Abogada Universidad Nacional de Colombia, especializada en Derecho Penal y Ciencias Forenses, se desempeñó como juez de conocimiento y juez de control de garantias, correo electrónico: andreasanchezgil@hotmail.com

3 Abogado Universidad Nacional de Colombia, especializado en Derecho Penal y Ciencias Forenses, y en Derecho Constitucional y Administrativo, se ha desempeñado como fiscal especializado y Delegado ante el Tribunal, correo electrónico: javierjaac@yahoo.es 


\section{COMO CITAR ESTE ARTÍCULO (APA 6)}

Sánchez Gil, Illiana Andrea; Alcárcel Cepeda, Javier Alberto (2017). Estudio de constitucionalidad del parágrafo del articulo 57 de la Ley 1453 de 2011. Revista Jurídica Mario Alario D’Filippo, IX (17), pág. 70-94.

\section{RESUMEN}

La Ley 1453 de 2011, en el parágrafo del articulo 57, redujo el beneficio de descuento punitivo consagrado en el articulo 351 del C.P.P. cuando el imputado se allana a cargos, y fue declarado exequible por la Corte Constitucional a través de la sentencia C-645 del 24 de agosto de 2012. Este trabajo realiza un estudio de dicha normatividad a la luz de los principios de igualdad, legalidad, proporcionalidad, lealtad procesal, y además las garantias consagradas e integradas por vía del bloque de constitucionalidad, de lo cual se concluyó que no solo atenta dicha normatividad contra la estructura del sistema penal acusatorio y las garantias precitadas, sino contra los parámetros trazados por los diferentes instrumentos internacionales suscritos y aprobados por Colombia que se han integrado a nuestro ordenamiento interno, toda vez que desconoce principios hermenéuticos que estructuran el favor rei como es el pro homine, pues ignora la interpretación más favorable en términos de sanción punitiva y de libertad del justiciable. Se deja en evidencia la falta de coherencia de la política criminal del Estado y el poco rigor jurídico en la decisión analizada de la Corte Constitucional.

\section{PALABRAS CLAVE}

Inconstitucionalidad, proporcionalidad, legalidad, lealtad procesal, igualdad, principio pro homine

\section{ABSTRACT}

The paragraph of article 57 of the Colombian Law 1453 of 2011 reduced the benefit of punitive discount enshrined in article 351 of the Criminal Procedure Code when the defendant acquiesces to the charges. This law was declared constitutional by the Constitutional Court through Judgment C -645 of august 24, 2012. The purpose of this paper is to analyze this law in the light of the principles of equality, legality, proportionality, procedural loyalty, as well as the guarantees established and integrated in the Colombian legal system through the constitutionality block. Based on such analysis, the author concluded that, not only does the law attempt against the structure of the adversarial system and the guarantees mentioned above, but also against the parameters set by the various international instruments signed and ratified by Colombia that have been integrated into our domestic law, as it ignores hermeneutical principles that structure the favor rei such as pro homine by ignoring the most favorable interpretation in terms of punitive measures and freedom of the defendant. The lack of coherence of the criminal justice policy and the deficiency in the legal rigor and analysis in the decision of the Constitutional Court is evidenced in this law.

\section{KEY WORDS}

Unconstitutional, proportionality, legality, procedural fairness, equality, pro homine. 


\section{INTRODUCCIÓN}

La sociedad está bien ordenada cuando

los ciudadanos obedecen a los magistrados

y los magistrados a las leyes.

Solón

Como quiera que en Colombia la justicia penal se adscribía a un sistema inquisitivo de orden continental europeo, caracterizado por la permanencia de la prueba, donde se desarrollaba una investigación por un funcionario que posteriormente en juicio habría de convertirse en contraparte de la defensa, es decir, era juez y parte, donde incluso se llegó a permitir por un breve período de tiempo la práctica de pruebas secretas y protección de la identidad de los testigos, prevaleciendo el manejo escritural y reservado de los elementos que soportaban las decisiones de los funcionarios, se vio entonces la necesidad de acompasar el sistema penal colombiano con uno que permitiera materializar los compromisos que Colombia había suscrito a nivel internacional a través de diferentes instrumentos que consagraban garantias tanto para las personas procesadas, como para las víctimas de conductas punibles. Es así como desde el año 2005, se implementó en Colombia un nuevo procedimiento penal, que se contrapone al preexistente, en la medida que dentro de sus principales características se tiene que es un sistema de carácter adversarial, que existe una demarcada diferenciación de roles de los sujetos procesales, que es de carácter rogado y premial, así como que frente a la prueba obran los principios de inmediación y concentración, con lo cual se elimina la permanencia de la misma.

Ahora bien, se entiende como justicia premial el otorgar beneficios a los procesados que colaboren con la administración de justicia, bien sea por aceptar los cargos imputados por la fiscalía en diversas etapas procesales a cambio de una reducción sustancial de la pena a imponer, así como lograr rebajas punitivas por reparar integralmente a la víctima antes de dictarse sentencia, con el fin de aplicar justicia de manera célere, eficaz y restaurativa.

Esasícomoparaelaño 2011, seintrodujeronmodificacionesatravésdelaimplementación de la ley 1453, entre ellas reducir drásticamente el beneficio de descuento punitivo a las personas que se allanen a cargos en audiencia de imputación, cuando se hubiera producido su captura en flagrancia. Luego de múltiples interpretaciones realizadas por los operadores judiciales, la Corte Constitucional mediante sentencia C-645 de agosto 24 de 2012, declaró exequible dicho articulo, en el entendido que se extendiera a todas las etapas procesales la reducción del descuento punitivo.

No obstante lo anterior, existen una serie de elementos que se deben considerar, a la luz de los instrumentos internacionales, para verificar la concordancia entre lo dispuesto por el legislador en el parágrafo del articulo 57 de la Ley 1453 del 24 de junio de 2011, 
como el pronunciamiento contenido en la sentencia C-645 del 24 de agosto de 2012, con lo dispuesto en diferentes pactos internacionales incorporados al ordenamiento jurídico colombiano por vía del bloque de constitucionalidad, y, más aún, si existe una clara y flagrante violación al principio de independencia de los poderes consagrada en el articulo 113 de la Carta Política, y la expresa prohibición de desbordar las funciones inherentes y taxativas correspondientes a cada una de las autoridades que rigen al Estado, contenida en el canon 121 de la Constitución, respecto de la decisión de la Corte Constitucional al declarar exequible dicho articulo que contempla la reducción del descuento punitivo, a la vez que lo extiende a las demás etapas procesales, con lo cual eventualmente se habría invadido la órbita del legislador y atentado contra el principio pro homine consagrado en el articulo $5^{\circ}$ del Pacto de Internacional de los Derechos Civiles y Políticos y en el articulo 29 de la Convención Americana de Derechos Humanos.

Esimportantereflexionarsiefectivamentesoncoherenteslosanteriorespronunciamientos del legislativo y de la Corte Constitucional, con lo pretendido por el mismo legislador en el Acto Legislativo 03 de 2002, mediante el cual se dio vía libre a la implementación del sistema penal acusatorio, a través del cual el Estado Colombiano buscaba materializar el principio de eficiencia de la actividad procesal del régimen punitivo, por intermedio de herramientas viables que acortaran el procedimiento y le ahorraran al Estado el desgaste de una investigación penal. Resulta igualmente de trascendencia jurídica verificar si no se ha conculcado el principio de igualdad ante la ley consagrado en el articulo 13 de la Constitución, que debe obrar frente a todos los ciudadanos que componen la nación colombiana, y más aún para aquellos que soportan el actuar represivo del Estado, cuando se hace una diferenciación entre capturados en flagrancia y los que no ostentan dicha calidad, si a la luz del nuevo sistema procedimental penal no existe la permanencia de la prueba y la misma solo se produce en el juicio, con lo cual no representa ningún plus para la actividad punitiva la condición de flagrante, y muy por el contrario, una conducta cometida por dos sujetos podrá ser penada de manera distinta, solo por el momento y las condiciones de su captura.

Es objeto de análisis comprobar si no se está en contravía de los intereses de la propia víctima, al posponer su derecho a la verdad, a la justicia, y eventualmente a la reparación, postergando la materialización de los mismos hasta agotar todo el procedimiento penal, por el solo hecho de no mantener un descuento punitivo realmente benéfico para el agresor, que lo motive a aceptar su responsabilidad penal, el cual se muestra acorde con la justicia premial que se pretendió imponer a través del acto legislativo 03 de 2002. Luego, se presenta como relevante constatar si los cuestionados pronunciamientos del legislativo y la Corte Constitucional, se pueden afirmar y reconocer como acordes con los parámetros constitucionales y del bloque de constitucionalidad.

La temática expuesta en precedencia se abordó realizando una comparación entre el parágrafo del articulo 57 de la ley 1453 de 2011 y el bloque de constitucionalidad, 
integrado por la Constitución Nacional, los tratados internacionales suscritos por Colombia y los principios rectores del Código Procedimental Penal [CPP], desarrollando los conflictos que presenta frente al derecho a la igualdad, el derecho de las víctimas, a la naturaleza misma del sistema penal acusatorio, los principios que lo rigen, el principio pro homine, según el cual "se debe acudir a la norma o la interpretación más amplia, cuando se trata de reconocer derechos, e, inversamente, a la norma más restringida cuando se trata de restringir de manera permanente el ejercicio de los derechos y su suspensión extraordinaria" (Gutiérrez, 2009, p. 27). De acuerdo con lo anterior, resulta procedente enmarcar el decurso de la investigación dentro de la escuela de la Investigación Jurídica. Se realizará un análisis de las garantias constitucionales, y los principios que rigen el sistema penal acusatorio en contraposición de lo normado en el articulo multicitado. En segundo lugar se hará una reflexión de la decisión de la Corte Constitucional (Corte Constitucional de Colombia, Sent. C-645, 2012) a partir del principio pro homine, para finalmente llegar a una conclusión sobre la adecuación o no de la norma en cita a los cánones constitucionales y supraconstitucionales.

Al final de ello se concluirá que, pese a la declaración de constitucionalidad del articulo 57 de la ley 1453 de 2011, según sentencia C-645 (Corte Constitucional de Colombia, Sent. C-645, 2012), dicha norma es inconstitucional porque desnaturaliza la ley 906 de 2004, pues va en contravía de la política criminal del Estado, además de violar flagrantemente garantias fundamentales de los sujetos procesales.

\section{PROLEGÓMENO}

De manera preliminar debe señalarse que el articulo 4으 de la Constitución Nacional establece el principio de supremacía constitucional, es decir que frente a un conflicto entre una norma de menor jerarquía y las disposiciones constitucionales prevalecen estas últimas, de tal suerte que existe un control constitucional sobre las normas de menor rango, las cuales deben respetar los principios basilares en los cuales se fundamenta el Estado Social, Democrático y de Derecho.

Así las cosas se entrará a analizar si el parágrafo del articulo 57 de la ley 1453/11 atenta contra las disposiciones constitucionales, específicamente, por erosionar los principios de legalidad, debido proceso e igualdad, y por dar al traste con la coherencia normativa del sistema acusatorio implementado por el constituyente en el Acto Legislativo 03 de 2002.

\section{PRINCIPIO DE LEGALIDAD}

El principio de legalidad surgió como una garantia de los ciudadanos, protegiéndolos frente a un eventual desborde del Estado en el ejercicio del lus Puniendi y como límite al arbitrio judicial. 
El principio de legalidad, se aprecia, como un derecho fundamental consagrado en el articulo 29 de la Constitución Nacional que exige ley previa y respeto del debido proceso, el cual a su vez se desarrolla en el articulo $10^{\circ}$ del Código Penal que establece: "La ley penal definirá de manera inequívoca, expresa y clara las características básicas estructurales del tipo penal".

No pocas veces la Corte Constitucional ha considerado contraria a la constitución normas cuando son vagas, imprecisas y su interpretación es susceptible de entendimientos diversos por los aplicadores de justicia, máxime en la presente hipótesis cuando se trata de determinar la consecuencia jurídica de una conducta punible, cual es, el monto de la pena, en eventos como los allanamientos a cargos y las negociaciones.

Lo anterior, en razón a que con fundamento en el articulo 29 de la Constitución Nacional, toda norma penal, debe ser escrita, clara y expresa, máxime cuando conlleva limitaciones a los derechos fundamentales, requisitos que no solo recaen sobre descripciones tipicas de toda conducta con relevancia penal, sino que por lógica de las consecuencias jurídicas que de allí se derivan entiéndase la pena a imponer.

En este orden de ideas, como la norma estudiada no tiene la claridad que debe tener toda norma penal que incide en la tasación de la pena, pues a pesar de los múltiples esfuerzos hermenéuticos continua siendo una norma oscura que conduce a la indeterminación de la pena, debe concluirse que es contraria a la Constitución y en especial al articulo 29 de dicha obra.

A modo de ejemplo, se tiene que en un intento fallido por darle claridad a la norma en sentencia 36.502 (Corte Suprema de Justicia, Sent. 36.502, 2011) se señaló que el monto de la rebaja debe ser del veinticinco por ciento de la pena a imponer, en todas las fases procesales, disintiendo de dicha interpretación apoyada en forma mayoritaria por la sala penal, mediante salvamento de voto el magistrado Sigifredo Espinoza indicó que esa cuarta parte de la rebaja de pena el legislador la estableció sobre el monto del beneficio, que oscila entre una tercera parte y un día a la mitad de la pena imponible, y no sobre la totalidad de la misma, y que una interpretación contraria a ello invadiría la órbita del legislador.

Así las cosas, al estudiar la norma en comento, se encuentra que es una norma mal redactada, que ha dificultado su aplicación, dadas las múltiples interpretaciones posibles de la cual ha sido objeto por parte de los operadores judiciales, sin que se logre consenso, ni siquiera en la Sala Penal de la Honorable Corte Suprema de Justicia.

Así mismo los doctrinantes han indicado que toda norma restrictiva que limite derechos fundamentales debe cumplir requisitos esenciales para que se ajuste a la Constitución en sentido amplio: 
El principio de legalidad determina que toda medida (incluso las permisivas, protectoras, garantizadoras) limitativa de derechos fundamentales se encuentre prevista por normas jurídicas, atendiendo al principio de Bloque de Constitucionalidad contentivo de la siguiente prescripción: en el caso en que una norma jurídica tenga por objeto limitar, afectar o restringir derechos fundamentales u ordinarios deberá observar los siguientes requisitos: (i) debe ser escrita, expresa, taxativa, clara; (ii) no admite interpretación analógica, extensiva ni deductiva en otras modalidades y (iii) solamente admite interpretación literal. Se suma, que la decisión de limitación, afectación o restricción ha de provenir de un ente constitucionalmente predeterminado para tal efecto (González \& Cuellar, 1990, p. 69)

No obstante en sentencia de constitucionalidad (Corte Constitucional de Colombia, Sent. C-645, 2012), se indica cual es la interpretación que debe dársele a dicha norma, declarando su exequibilidad condicionada en ese entendido, ut infra se verá como esa deducción atenta contra la división de poderes y contra principios fundamentales del justiciable.

\section{DEBIDO PROCESO}

El Debido Proceso es un principio constitucional que se encuentra inmerso igualmente en el articulo 29 de la Constitución Nacional.

Sobre este derecho debe indicarse que es una regulación establecida por ley o reglamento que señala de manera previa el procedimiento al cual se deben sujetar las partes involucradas, de manera que no dependen del arbitrio de las autoridades, sino que encuentra su límite en el imperio de la norma que regla el proceso en cuestión

\subsection{SOBRE EL PRINCIPIO DE PROPORCIONALIDAD QUE HACE PARTE DEL DEBIDO PROCESO}

El principio de proporcionalidad de manera genérica debe entenderse como otorgarle a cada cual lo que le corresponde, este principio ha sido profusamente desarrollado por múltiples estudiosos del derecho, reivindicando su importancia y prevalencia. "Dado que es una máxima del Derecho -el que las leyes deban guardar cierto grado de razonabilidad o proporcionalidad para ser conformes a la Constitución-, se ha elevado esta exigencia a nivel de principio constitucional" (Sapag, 2008, p. 162).

La proporcionalidad en sí misma es un equilibrio entre derechos en tensión:

“El principio de proporcionalidad cuenta con una bifurcación, para analizar, si el enfrentamiento de posiciones normativas deviene de una falencia del sistema, o de una dinámica de exceso, que en uno y otro caso desconocería la noción de equilibrio que pretende el principio de pretensión de corrección del sistema jurídico" (Londoño, 2011, p.132). 
Así las cosas, toda medida que violente el principio de proporcionalidad, se encuentra por fuera del marco constitucional:

"Prohibiéndose constitucionalmente el exceso y el defecto en el devenir del orden jurídico, se constituyen formas del principio de proporcionalidad tendientes a establecer si una decisión jurídica configura una situación exagerada, extralimitada, desbordada, desmedida, o, falente, carente, escasa, o reducida frente a la protección, promoción o reducción del ejercicio de los derechos fundamentales (...)" (Londoño et al).

Sobre el caso de estudio, debe advertirse que no obstante la decisión de la Corte Constitucional sobre la norma en comento, el parágrafo del articulo 57 de la ley 1453, solo modificó el articulo 351 de la Ley 906 de 2004, que se refiere a las rebajas por aceptación de cargos en la imputación y por vía de preacuerdos hasta la formulación de la acusación, pero no modificó los articulos 352 y 356 numeral 5으, que establecen una rebaja de hasta una tercera parte de la pena si el allanamiento o preacuerdo es en la audiencia preparatoria, así como tampoco modificó el articulo 367 que concede una rebaja de una sexta parte de la pena si esta figura se presenta al inicio del juicio oral.

Así pues, sobre la materialización del principio de proporcionalidad que, en el ámbito penal, hace parte del debido proceso ${ }^{4}$, en el marco del procedimiento penal acusatorio, particularmente, en la proporcionalidad de los beneficios punitivos en relación con la etapa procesal en que se efectúa el allanamiento a cargos por parte del indiciado, ha establecido la Corte Constitucional, haciendo una explicación de dicha figura procesal:

Una visión sistemática de la manera como están concebidos los rangos de descuento punitivo por concepto de allanamiento a los cargos en el nuevo sistema, dependiendo del momento en que se produzca, permite establecer que existe una concepción más favorable en el nuevo estatuto particularmente en lo concerniente al allanamiento a los cargos en el momento de su formulación (Corte Constitucional de Colombia, Sent. T-388, 2007).

Haciendo un análisis de cómo se encuentra materializado este principio de proporcionalidad en la Ley 906 de 2004, y cómo, de manera progresiva se va disminuyendo el descuento punitivo, conforme se va agotando el procedimiento, señaló la Corte:

Determinando la favorabilidad en abstracto, es preciso abordar el tema con una visión sistemática, y de conjunto de los diferentes rangos de descuento punitivo que la nueva normatividad establece, vinculando su magnitud a los estadios en que se produce el allanamiento a los cargos: (i) una rebaja de hasta la mitad de la pena imponible cuando el evento se produce en la audiencia de formulación de la imputación (Arts. 288.3 en c.c. con el 351); (ii) una rebaja de hasta una tercera parte de la pena a imponer, cuando el mismo evento se produce en desarrollo de la audiencia preparatoria (Art. 356.); (iii) un descuento

4 Sobre este criterio pueden consultarse, entre otras: Corte Constitucional, C-592, 2005, A. Tafur y T-393,2008, C.I Vargas 
de una sexta parte, cuando ocurre en el juicio oral (Art. 367 inc. $2^{\circ}$ ). Cuanto más distante se encuentre el proceso del juicio, el allanamiento genera un mayor reconocimiento punitivo $^{5}$ (Corte Constitucional de Colombia, Sent. T-091, 2006).

Puestas así las cosas, atenta de forma clara contra el principio de proporcionalidad de la pena en el procedimiento penal, que a la vez sirve de inspiración al descuento punitivo acorde a la etapa procesal en la que se produce el allanamiento a cargos establecido de forma cuidadosa y coherente por el legislador del año 2004, que el procesado que voluntariamente ha decidido aceptar su responsabilidad y contribuir así a la eficiencia de la justicia, reciba en la respectiva audiencia de imputación -un escenario inacabado de la acción penal- un descuento mucho menor al que tendría derecho si decide esperar, dilatando así el procedimiento, y allanarse en la correspondiente audiencia preparatoria o incluso en el juicio oral. Esa circunstancia, además de atentar contra la lógica jurídica que gobierna el procedimiento penal, castiga de forma inexplicable a quien ha decidido, motu propio, apoyar en la celeridad en la definición del caso, y premia con mayor descuento a quien opta por continuar con el proceso y extenderlo hasta llegar a un estadio que resulte más conveniente para él en lo que se refiere a la mencionada aceptación. El contraste con el postulado básico de proporcionalidad de la pena resulta, entonces, evidente.

\subsection{PRINCIPIO DE LEALTAD PROCESAL}

Como tercer elemento, se encuentra que la norma legal analizada vulnera de forma visible el principio elemental de lealtad procesal, que rige en todas las materias jurídicas y hace parte del conjunto del derecho fundamental al debido proceso ${ }^{6}$, máxime en un asunto tan delicado como el desarrollo del poder punitivo del Estado. Sobre esto último, y aterrizando en la materia objeto de análisis, es pertinente traer a colación la jurisprudencia de la Corte Constitucional, que al respecto establece:

Esta institución jurídica es una de las formas de terminación abreviada del proceso penal, y responde a una política criminal cuya finalidad es la de lograr mayor eficiencia y eficacia en la aplicación de justicia ${ }^{7}$, pues mediante ella se autoriza al juez para emitir el fallo que pone fin al proceso antes de agotarse o cumplirse todas las etapas procesales establecidas por el legislador, las que se consideran innecesarias, dada la aceptación por parte del procesado de los hechos materia de investigación y de su responsabilidad como autor o participe de los mismos. Dicha actuación por parte del procesado es catalogada como una colaboración con la administración de justicia que le es retribuida o compensada con una rebaja de pena cuyo monto depende del momento procesal en que ésta se realice (...) Contar con un sistema judicial eficiente, que no dilate los procesos y permita resolverlos oportunamente, sin desconocer las garantias fundamentales del procesado, es un deber del Estado y un derecho de todos los ciudadanos. Una política criminal que conceda

\footnotetext{
5 Resaltado de los autores

6 Sobre ello, consultar, entre otras: Corte Constitucional, C-670/2004, C.I. Vargas

7 Resaltado es de los autores
} 
beneficios a quienes actúen observando el principio de lealtad procesal, logrando además la aplicación de una justicia pronta y cumplida, sin desconocer ningún derecho o garantia del procesado, no puede tildarse de atentatoria de los derechos inalienables del individuo ${ }^{8}$ (Corte Constitucional de Colombia, SU-1300, 2001).

Resulta evidente para la Corte Constitucional, dentro del desarrollo de la política criminal, la necesidad de la existencia de un mecanismo que permita abreviar el proceso penal y evitar el desgaste de la justicia, y reconoce que un mecanismo de rebaja de pena, que no conculque ningún derecho o garantia del procesado, conlleva a la materialización de un sistema judicial eficiente. En la misma línea la Corte Constitucional ha reconocido en otros pronunciamientos la necesidad y el valor de la justicia premial enmarcado por la lealtad procesal:

La aceptación espontánea de los cargos se basa también en el principio de la buena fe, y de la lealtad procesal como deber de las partes en toda actuación judicial (Art. 12). Su ejercicio legítimo en materia de aceptación de cargos es promovido mediante descuentos punitivos $^{9}$ (Corte Constitucional de Colombia, T-091, 2006).

Desde dicho punto de vista, es palmario que no resulta una práctica leal para con el procesado, quien de buena fe ha resuelto prestar su colaboración en la recta y eficaz impartición de justicia, aceptando su responsabilidad y a la espera razonable de un beneficio punitivo acorde con ello, desconocer ese principio de confianza y otorgarle una rebaja de la pena ínfima en relación con aquella que se le aplicaría si decidiese intencionalmente dilatar el allanamiento por motivos de beneficio individual. Siendo esta, entonces, una justicia de carácter premial, constituye un absurdo jurídico caer con todo el peso punitivo de la ley sobre quien le ha ahorrado esfuerzo investigativo al sistema judicial y premiar a quien ha suspendido su colaboración hasta etapas procesales posteriores.

En otros términos, la reforma introducida por el parágrafo del articulo 57 de la Ley 1453 de 2011, al reducir de un tajo el beneficio establecido en el articulo 351 de la Ley 906 de 2004 y dejar intactos- y por tanto más amplios- aquellos estatuidos para estadios posteriores de la acción penal, está creando una discordancia injustificada y generando un estimulo perverso para que aquellos que se encuentren incursos en dicha acción, dilaten el funcionamiento de la justicia, paradójicamente, con el propósito de obtener mayores descuentos punitivos.

\section{EL DERECHO A LA IGUALDAD}

Por otra parte, como otro aspecto atentatorio de la Constitución Política, se encuentra que la norma analizada vulnera el derecho fundamental a la igualdad, en la medida en

8 Resaltado de los autores

9 Resaltado de los autores 
que, en tratándose del descuento punitivo por el allanamiento a cargos en la audiencia de imputación, introduce una distinción carente de justificación racional entre quienes son capturados en situación de flagrancia y aquellos que no se hallan en dicha circunstancia. En ese orden de ideas, esta desconoce principios básicos del procedimiento penal acusatorio $y$, sin apreciarse fundamentos de peso al respecto, ofrece un trato dispar a sujetos que, ante la justicia penal, se encuentran en igualdad de condiciones.

En efecto, a diferencia de lo que ocurría en vigencia de la Ley 600 de 2000 y otros regímenes procesales anteriores, bajo el imperio del sistema regulado por la Ley 906 de 2004, la captura en flagrancia no constituye, por sí sola, un medio probatorio con base en el cual se pueda determinar la responsabilidad del acusado pues, al igual que quienes no ostentan esta condición, estos solo pueden ser juzgados con base en las pruebas debidamente allegadas y debatidas en juicio oral, público, y bajo los principios de contradicción, inmediación y concentración. En otras palabras, la captura en flagrancia constituye, a lo sumo, una excepción al principio de reserva judicial en materia de privación de la libertad del indiciado, más no una prueba irrefutable para condenar a quien se encuentra, repetimos, en igualdad de condiciones frente a la persona que no es capturada en flagrancia, debiéndose para ambos, en todos los casos, surtir la práctica de las pruebas en pleno juicio oral con todas las garantias procesales aplicables.

Sobre ello la Sala de Casación Penal de la Corte Suprema de Justicia, fue enfática al señalar que:

No puede descuidarse, y en ello no repara el planteamiento del demandante, que en la Ley 906 de 2004 no impera el principio de permanencia de la prueba ${ }^{10}$ como podía ocurrir con el ordenamiento procedimental regulado en la Ley 600 de 2000 y los que le antecedieron, en los que en el juicio era admisible la consideración de pruebas incorporadas a la actuación durante la fase de instrucción (Corte Suprema de Justicia, Sent. 25136, 2006).

Es claro que frente al tema probatorio, al no operar la permanencia de la prueba, existe una situación igual, tanto para el capturado en flagrancia como para el que no, toda vez que la prueba solo se constituye en el juicio oral con el cumplimiento de los requisitos de publicidad, oralidad, inmediación y contradicción. Sobre ello la Corte Constitucional indicó:

Las modificaciones introducidas al proceso penal mediante el Acto Legislativo 03 de 2002 inciden en el régimen probatorio, por cuanto la construcción de la prueba cambia de escenario, en el sentido de que se abandona el principio de permanencia de la prueba, según el cual las pruebas practicadas por la Fiscalía General de la Nación desde la indagación preliminar tienen validez para dictar una sentencia, por aquellos de concentración e inmediación de la prueba practicada en el curso de un juicio oral, público y con todas las garantias. De tal suerte que los elementos materiales probatorios y las evidencias

10 Resaltas de los autores 
recaudadas durante la investigación, si bien sirven de soporte para imponer medidas restrictivas al ejercicio de los derechos fundamentales, no pueden ser el fundamento de una sentencia condenatoria, decisión que debe estar soportada en pruebas practicadas durante el juicio oral. En tal sentido, la prueba deja de encontrarse dispersa en varios escenarios procesales, escrita, secreta y valorada por un funcionario judicial que no tuvo incidencia en su recaudo, para ser practicada en forma concentrada en el curso de un juicio oral, público y con todas las garantias procesales. (Corte Constitucional de Colombia, Sent. C-591, 2005).

De lo anterior se desprende, entonces, que siendo las condiciones probatorias iguales tanto para quien se encuentra en situación de flagrancia como para quien no se halla inmerso en tal supuesto fáctico toda vez que, independientemente de la situación, deben observarse para todos los indiciados los mencionados principios y rigores formales del procedimiento acusatorio, la aceptación de cargos constituye, para cada uno de ellos, un acto de colaboración con la justicia, que representa el mismo ahorro en esfuerzo investigativo, merece el mismo valor y, por consiguiente, la misma retribución en materia de rebaja punitiva. Lo contrario encarna, sin lugar a dudas, una violación al derecho a la igualdad que supone, en su núcleo esencial, tratar igual a quienes, valga la redundancia, se encuentran en igualdad decondiciones.

Al respecto, finalmente, cabe agregar que si bien en dos ocasiones la Corte Constitucional ha convalidado la exequibilidad de normas que otorgan un tratamiento procedimental distinto a quienes sean capturados en situación de flagrancia ${ }^{11}$, dicho precedente no es aplicable al caso que nos atañe, por tratarse de una diferenciación legislativa realizada en relación con otros aspectos del procedimiento penal, a saber, la exclusión del requisito de denuncia para la iniciación de la acción en tratándose de delitos querellables cuando concurre la flagrancia, y únicamente con el fin de promocionar medidas que aseguren la comparecencia del capturado y velar por la protección de las víctimas del delito, lo cual nada tiene que ver con la hipótesis subjudice en donde, a personas que están en igualdad de condiciones frente a un juicio público y concentrado, con inmediación de las pruebas, y que con su allanamiento contribuyen por igual a la agilidad y el ahorro en el funcionamiento de la justicia, se les otorga injustificadamente un descuento punitivo dispar.

Mas grave resulta aún, en el evento de un hecho delictivo cometido por dos personas, y una de ellas es capturada en flagrancia y la otra no, frente a un eventual allanamiento a cargos realizado por ambos sujetos activos en la audiencia de imputación, las consecuencias punitivas para uno y otro, serían abismalmente distintas, no obstante, estén en idénticas condiciones frente al delito cometido, grado de participación y circunstancias post delictuales como la aceptación de cargos en la misma etapa procesal, como se observa en este caso se estaría condenando por los mismos hechos a diferentes sanciones punitivas, 
sin explicación plausible para ello, con lo cual se trasgrede evidentemente el principio constitucional.

\section{SOBRE EL SISTEMA PENAL ACUSATORIO}

Igualmente se encuentra que el parágrafo del articulo 57 de la Ley 1453 de 2011 resulta contrario a la Constitución toda vez que rompe y desnaturaliza por completo la coherencia lógico-procedimental que caracteriza a la justicia penal acusatoria ideada por el Constituyente en la reforma introducida desde el año 2002, y desarrollada cuidadosamente por el legislador en la Ley 906 de 2004. En efecto, dicho giro en la Carta Política y su consecuente reglamentación legal fueron diseñados minuciosamente para garantizar una correspondencia racional entre todas las etapas procesales de la acción penal dentro de este sistema, al igual que el respeto a las garantias de las partes.

Tal diseño, pues, se sostiene en un delicado equilibrio que resulta trastocado por una reforma legal que pervierte y desestabiliza la coherencia del sistema acusatorio, en desmedro, por supuesto, de la celeridad de la justicia y los derechos tanto del indiciado comodelasvíctimas, aldesvirtuarsucarácterdejusticiapremialyeficaz, yviolarelprincipio de proporcionalidad que en esta materia supone, obviamente, establecer una rebaja punitiva que se compadezca con la etapa procesal en la que tiene lugar el allanamiento, dándole mayores ventajas a quien acepta cargos en un momento temprano de la acción, y menores a quien lo hace posteriormente, y esta normatividad, se reitera, implica todo lo contrario. La Corte Constitucional reconoció en pretéritos pronunciamientos, la necesidad de efectivizar el principio de gradualidad punitiva, conforme a la fase en que tuviere lugar el allanamiento, así:

De las anteriores referencias normativas se infiere claramente que la nueva ley procesal contempla los diferentes estadios procesales (audiencia de formulación de imputación, audiencia preparatoria y juicio oral) en que es posible al procesado realizar una aceptación unilateral de cargos - allanamiento -, previendo a su vez la consecuencia punitiva gradual que se deriva de tal actitud procesal, acorde con cada uno de esos momentos. Una rebaja de hasta la mitad de la pena, cuando la aceptación se produce en la diligencia de imputación, de hasta una tercera parte cuando ocurre en la audiencia preparatoria y de una sexta cuando se presenta en la alegación inicial del juicio oral.

\section{(...)}

La aceptación unilateral de cargos, conforme a la Ley 906 de 2004, la cual se puede producir en diversas etapas procesales, responde a una naturaleza similar en cuanto representa una forma de terminación anticipada del proceso, e involucra cometidos de política criminal similares como son los de lograr una mayor eficiencia y eficacia de la administración de justicia, prescindiendo de etapas procesales que se consideran innecesarias en virtud de la aceptación del procesado respecto de los hechos y su responsabilidad como autor o participe de los mismos. Los dos institutos envuelven una especie de colaboración con 
la administración de justicia retribuida o compensada mediante una rebaja de pena proporcional al momento procesal en que la aceptación de responsabilidad se produce.

En el modelo de procesamiento diseñado en la Ley 906 de 2004 la promoción del valor de la eficiencia del sistema vinculado a la preservación de garantias fundamentales cobra mayor importancia en la medida que se trata de una aspiración que se encuentra en el centro del ideario de un sistema de corte acusatorio y se erigió en uno de los argumentos que impulsaron la reforma.(Corte Constitucional de Colombia, Sent. T-356, 2007).

Y es evidente que la Corte, de manera pacífica, había venido aceptando la aplicación de dicha gradualidad punitiva, acorde con una lógica jurídica, como cuando señala:

Como parte esencial del nuevo sistema, el imputado o acusado tiene la facultad de renunciar a algunas garantias, en virtud de la aceptación de los cargos por iniciativa propia o de la celebración de acuerdos con la Fiscalía, con el fin de terminar anticipadamente el proceso y lograr a cambio una rebaja de la pena imponible. Dicha facultad puede ejercerse a lo largo del proceso, desde la audiencia de formulación de la imputación hasta el momento en que sea interrogado el acusado al inicio del juicio oral (Arts. 350, 352 y 367 Ley 906 de 2004), de suerte que la rebaja será mayor al comienzo de dicho intervalo y menor al final del mismo (Corte Constitucional de Colombia, Sent. C-1195, 2005).

De la misma manera, sobre la coherencia procedimental y los derechos de las partes, particularmente de las víctimas de las conductas punibles, ha afirmado la Corte:

En un Estado Social de Derecho el proceso penal se erige en un instrumento racional, conformado por diversas etapas y ritualidades, rodeado igualmente de un conjunto de garantias judiciales, encaminado a determinar la posible responsabilidad penal de un individuo, cuya conducta habría injustamente vulnerado uno o varios derechos fundamentales (vgr. vida, integridad personal, libertad individual, etc) o determinados bienes jurídicos constitucionalmente relevantes (patrimonio público, salubridad pública, orden económico y social, etc.). En efecto, cualquier proceso penal tiene como finalidad principal la determinación de la responsabilidad penal individual. En tal sentido, se puede afirmar que aquél se encuentra conformado por un conjunto de actos jurídicos y de etapas que guardan, entre sí, una relación cronológica, lógica y teleológica: unos son soporte y presupuesto de los otros, y todos se orientan hacia un mismo fin, cual es, establecer, más allá de toda duda razonable, si una persona es o no responsable por la comisión de un determinado delito. De allí que resulte inconcebible un proceso penal que no se oriente a la consecución de tales cometidos. Ahora bien, en un Estado Social de Derecho, el proceso penal está llamado a cumplir otras importantes finalidades, que van más allá de la determinación de la responsabilidad penal del individuo. En efecto, en los últimos años, merced a la evolución del derecho internacional de los derechos humanos, el respeto y la garantia de los derechos sustanciales de las víctimas se han erigido en fines igualmente valiosos del proceso penal. En tal sentido, la actividad investigativa y sancionatoria del Estado no se limita a determinar la ocurrencia de una determinada conducta ilícita, al igual que sus autores y participes, y en últimas, a tasar e imponer una determinada pena, sino que debe apuntar asimismo a la consecución de otros fines, tales como la materialización de 
los derechos de las víctimas a la verdad, la justicia y la reparación ${ }^{12}$ (Corte Constitucional de Colombia, Sent. C-828, 2010).

Así las cosas, es claro que una disposición legal como la implementada en el parágrafo del articulo 57 de la ley 1453 altera de manera fuerte el engranaje procedimental diseñado por el Constituyente y el legislador de 2004, en la medida que desvirtúa los fines de justicia pronta, respetuosa de los derechos de las partes y fundamentada en el debido proceso que inspiraron la implementación del sistema, pues no solamente invierte indebidamente el carácter premial del proceso, subvirtiendo y distorsionando su esencia, sino que les arrebata a los sujetos procesales el derecho a conocer, en el menor tiempo posible, la verdad de los hechos y, si es del caso, obtener una oportuna reparación de las víctimas, con lo cual se conculcan los derechos y garantias de las mismas.

No es difícil observar, conforme a la praxis judicial, que en la medida que se restrinjan los beneficios de orden punitivo, menor será la implementación de la vía de terminación anticipada del proceso, pues resulta claro que los investigados habrán de preferir acudir a un juicio oral, que se presenta como incierto en sus resultados, a llegar a una aceptación de cargos, que inexorablemente le conllevará una condena, lo cual en últimas repercutirá en desmedro del eficientismo que se erige como la base que soporta la dinámica que rige el sistema penalacusatorio.

\section{SOBRE LA DECLARATORIA DE EXEQUIBILIDAD DEL PARÁGRAFO DEL ARTÍCULO 57 DE LA LEY 1453 DE 2011}

Sobre el parágrafo del articulo 57 de la Ley 1453 de 2011, realizó estudio de constitucionalidad la Alta Corte a través de la sentencia C-645 del 23 de agosto de 2012, con ponencia del magistrado Nilson Pinila Pinilla, retomando casi en su integridad la sentencia de la Corte Suprema de Justicia del 5 de septiembre de 2011 con radicación 36502, la cual fue transcrita en múltiples apartes, la Corte realizó los siguientes señalamientos:

Los factores a tener en cuenta para efectos de ponderar el monto de la reducción de la pena deben obedecer a elementos post delictuales como la colaboración con la justicia para el descubrimiento de otros participes o de otras conductas delictivas, reparación de la víctima y la mayor o menor economía procesal que se derive de esa aceptación de cargos. Por tanto no es solo el ahorro en el trámite procesal sino que aun más importante es el descubrimiento de la realidad material.

Así las cosas en los casos de la flagrancia en que no exista un "plus" de colaboración, la rebaja de penas no puede ser la máxima, así la economía procesal sea mayúscula.

12 El resaltado es de los autores 
Por tanto no puede operar el máximo beneficio en una situación de allanamiento ante una situación de flagrancia de donde se deriven sin mayor dificultad los elementos de convicción que permiten, un fallo condenatorio. Ello en virtud que este allanamiento no ofrece sino simplemente economía procesal y el premio a esa sola consecuencia se refleja justa y proporcionadamente en el 35 o $40 \%$, toda vez que en esas condiciones con aceptación de cargos o sin ella, surge mérito para condenar.

Consideración que fue acogida por el legislador y lo condujo a modificar el articulo 301 de la ley 906 de 2004, mediante el articulo 57 de la ley 1453 de 2011, “aunque su redacción no ofrece la claridad que se espera de una norma procesal con efectos sustanciales, dando lugar a diferentes interpretaciones"; esa modificación legislativa "es una inconsistencia más del legislador de los últimos años" con lo cual se dio lugar a que el imputado capturado en flagrancia esperara hasta otras etapas procesales para obtener una mejor rebaja punitiva.

No obstante el legislador omitió señalar qué ocurriría en los casos en que existiendo flagrancia, el imputado acepte los cargo formulados, en una etapa posterior, aceptar que, como no se modificaron la normas que regulan rebajas posteriores a la imputación, estas quedaron incólumes, es una tesis inaceptable que atentaría contra los principios de igualdad y seguridad jurídica, y contra el de progresividad o la filosofía del propio instituto, la cual es que a mayor colaboración y mayor economía procesal, más significativa ha de ser la respuesta premial, por tanto la $1 / 4$ parte de la rebaja de pena, en caso de flagrancia, tiene aplicabilidad con independencia de la etapa del proceso en la cual se presente la aceptación de cargos.

Así mismo, entender que se debe aplicar un descuento punitivo siempre de una $1 / 4$ parte de la pena afectaría la autonomía e independencia de la administración de justicia, como quiera que impediría al operador judicial ejercer la discrecionalidad, bien sea la fiscalía para negociar o al juez para fijar la pena.

Interpretaciones como las reseñadas desconocen principios como el de legalidad, igualdad y seguridad jurídica, sin embargo, no puede por ello predicarse la inexequibilidad del parágrafo del articulo 57 de la Ley 1453 de 2011, pues un fallo en ese sentido anularía la finalidad legítima del legislador de procurar una razonable distinción a los beneficios punitivos entre aquellas personas que son sorprendidas en flagrancia y quienes no lo son. Ante el silencio que guardó el legislador, lo imperativo es acoger aquella interpretación que se ajusta a la Constitución, en aplicación del principio de conservación del derecho, de modo que se salvaguarde la finalidad procurada por el Congreso en el ejercicio de su actividad democrática.

No se trata en el presente evento de una analogía in malampartem, como se indica en un segmento de la intervención realizada por el Tribunal Superior de Medellín, sino de 
una interpretación acorde con la Constitución, que permite hacer efectivos sus principios y valores superiores, máxime cuando la doctrina especializada indica que tal prohibición sólo tiene cabida con relación a los tipos penales o al aumento de la punibilidad.

Con todo, la doctrina especializada puntualiza que tal restricción se relaciona directamente con las partes general y especialde los Códigos Penales:

La prohibición de la analogía tiene aplicación en la Parte especial de la legislación penal en cuanto a la determinación literal del tipo y también respecto a la pena que se conmina. En cuanto a la Parte general debe prohibirse la analogía a cualquier precepto que amplié la punibilidad más allá de los tipos de la Parte especial. (Jauchen, 2005, p.93).

Puntualizado lo anterior, en el presente asunto la Corte Constitucional realiza no una interpretación analógica in malampartem, no sólo porque no es propia para el presente evento, pues no se trata de un tema relacionado con un tipo penal en específico, o un supuesto para ampliar la punibilidad, sino de una hermenéutica que ajusta la norma demandada al texto superior.

Bajo esos parámetros, lo predicable es que la Corte realice una interpretación del parágrafo demandando, que se ajuste a la Constitución, salvaguardando así principios superiores como la legalidad, la igualdad, la proporcionalidad y la seguridad jurídica, y la finalidad del sistema premial y negocial inherente al sistema procesal penal con tendencia acusatoria.

La hermenéutica adecuada del parágrafo del articulo 57 de la Ley 1453 de 2011, en lo que respecta a la limitación de los beneficios punitivos en caso de allanamiento o aceptación de cargos y preacuerdos o negociaciones entre la fiscalía y el imputado o acusado, cuando exista flagrancia resulta aplicable no sólo cuando esa forma de terminación anticipada del proceso tenga lugar en (i) la audiencia de formulación de la imputación (hasta en 1/4 parte del beneficio, que allí es hasta la mitad de la pena individualizada, es decir, entre un día y el $12,5 \%$ de la pena a imponer); también en posteriores actuaciones como durante (ii) la audiencia de formulación de acusación (hasta en 1/4 parte del beneficio a otorgar que es hasta $1 / 3$, esto es, entre un día y el $8.33 \%$ de la eventual pena) y (iii) en el juicio oral ( $1 / 4$ parte de la $1 / 6$ que allí se otorga, es decir, $4.16 \%$ de la pena respectiva).

La Corte Constitucional entonces declarará exequible el parágrafo del articulo 57 de la Ley 1453 de 2011, mediante el cual fue modificado el articulo 301 de la Ley 906 de 2004, en el entendido de que la disminución del beneficio punitivo en una cuarta (1/4) parte allí consagrado, debe extenderse a todas las oportunidades procesales en las que es posible allanarse a cargos y suscribir acuerdos con la Fiscalía General de la Nación, respetando los parámetros inicialmente establecidos por el legislador en cada uno de esos eventos donde se permite la discrecionalidad por parte de los operadores judiciales. 
Al respecto, es imperativo resaltar que la aplicación en sentido amplio de la norma demandada, respete los parámetros originalmente establecidos en la Ley 906 de 2004, cuando la terminación anticipada del proceso ocurra en una etapa distinta a la formulación de la imputación, y reconozca el margen que le es propio tanto a la Fiscalía para poder negociar, como al juez para fijar discrecional pero razonadamente la pena acorde con la efectividad que para la investigación y la economía procesal brinde el imputado o acusado.

\subsection{LA DECISIÓN DE LA CORTE CONSTITUCIONAL VS. EL PRINCIPIO PRO-HOMINE}

De arraigo en las fuentes del derecho internacional de los derechos humanos, en el marco de los diferentes instrumentos que lo estructuran, el principio pro homine se erige como una acotación y faro de las reglas orientadas a privilegiar, preferir, seleccionar, tutelar y acoger la aplicación de la norma que en mejor medida proteja los derechos fundamentales del ser humano. Es así como los tratados internacionales de derechos humanos han consagrado de manera expresa dicho principio, tal y como el Pacto Internacional de Derechos Civiles y Políticos (1966) [PIDCP] en su articulo $5^{\circ}$ ha previsto:

1. Ninguna disposición del presente Pacto podrá ser interpretada en el sentido de conceder derecho alguno a un Estado, grupo o individuo para emprender actividades o realizar actos encaminados a la destrucción de cualquiera de los derechos y libertades reconocidos en el Pacto o a su limitación en mayor medida que la prevista en él.

2. No podrá admitirse restricción o menoscabo de ninguno de los derechos humanos fundamentales reconocidos o vigentes en un Estado Parte en virtud de leyes, convenciones, reglamentos o costumbres, so pretexto de que el presente Pacto no los reconoce o los reconoce en menor grado.

A su turno la Convención Americana de Derechos Humanos (1969) [CADH] prevé en el canon 29:

Normas de Interpretación: Ninguna disposición de la presente Convención puede ser interpretada en el sentido de:

a. Permitir a alguno de los estados parte, grupo o persona, suprimir el goce y ejercicio de los derechos y libertades reconocidos en la Convención o limitarlos en mayor medida que la prevista en ella;

b. Limitar el goce y ejercicio de cualquier derecho o libertad que pueda estar reconocido de acuerdo con las leyes de cualquiera de los estados parte o de acuerdo con otra convención en que sea parte uno de dichos estados;

c. Excluir otros derechos y garantias que son inherentes al ser humano o que se derivan de la forma democrática representativa de gobierno, y

d. Excluir o limitar el efecto que puedan producir la Declaración Americana de Derechos y Deberes del Hombre y otros actos internacionales de la misma naturaleza 
Tenemos entonces que se impone como directriz interpretativa de los instrumentos internacionales mencionados, aquella que no va en contra o detrimento de los derechos que se protegen. Lo anterior enmarcado dentro del régimen interpretativo trazado y definido por la Convención de Viena sobre el derecho de los tratados, suscrita el 23 de mayo de 1969, la cual define en su articulo 31:

Interpretación de los tratados.

31. Regla general de interpretación

1. Un tratado deberá interpretarse de buena fe conforme al sentido corriente que haya de atribuirse a los términos del tratado en el contexto de éstos y teniendo en cuenta su objeto $y$ fin.

2. Para los efectos de la interpretación de un tratado. El contexto comprenderá, además del texto, incluidos su preámbulo yanexos:

a) todo acuerdo que se refiera al tratado y haya sido concertado entre todas las partes con motivo de la celebración del tratado;

b) todo instrumento formulado por una o más partes con motivo de la celebración del tratado y aceptado por las demás como instrumento referente al tratado;

3. Juntamente con el contexto, habrá de tenerse encuenta:

a) todo acuerdo ulterior entre las partes acerca de la interpretación del tratado o de la aplicación de sus disposiciones;

b) toda práctica ulteriormente seguida en la aplicación del tratado por la cual conste el acuerdo de las partes acerca de la interpretación del tratado;

c) toda forma pertinente de derecho internacional aplicable en las relaciones entre las partes.

4. Se dará a un término un sentido especial si consta que tal fue la intención de las partes. (Convención de Viena, 1969)

De lo anterior se tiene que, indefectiblemente, el principio pro homine, por su naturaleza hermenéutica, seerigecomomarcodelasreglasinterpretativasquedireccionanel Derecho Internacional De Los Derechos Humanos, que por vía de bloque de constitucionalidad, consagrado en el articulo 93 de nuestra Constitución, tiene grado supralegal, y por tanto se constituye en un principio fundante de las reglas por las cuales se ha de orientar la interpretación legislativa en el derecho interno.

Ahora bien, han previsto el PIDCP y la CIDH en sus articulos 4 y 274 respectivamente, la posibilidad de suspensión de garantias, dentro de las que se exceptúan en general aquellas relativas al reconocimiento de la personalidad jurídica, derecho a la vida, integridad personal, prohibición de esclavitud y servidumbre, principio de legalidad y de retroactividad, libertad de conciencia y de religión, protección a la familia, derecho al nombre, derechos del niño, derecho a la nacionalidad y derechos políticos, o de garantias judiciales para la protección de dichos derechos, enmarcado dentro de un estado de excepcionalidad, y solo en situaciones que pongan en peligro la vida y existencia de la nación, o, en caso de guerra, de peligro público o de otra emergencia que amenace la independencia o seguridad del Estado, lo cual debe ser informado a los demás Estados 
Parte. Sin embargo, a efectos de suspensión de garantias y libertades consagradas en los instrumentos, se impone la cláusula general de favorabilidad o cláusula de favorabilidad en la interpretación de los derechos humanos del sistema jurídico, o principio pro homine, que a la luz de lo señalado por la profesora Mónica Pinto:

Es un criterio hermenéutico que informa todo el derecho de los derechos humanos, en virtud del cual se debe acudir a la norma más amplia, o a la interpretación más extensiva, cuando se trata de reconocer derechos protegidos e, inversamente, a la norma o a la interpretación más restringida cuando se trata de establecer restricciones permanentes al ejercicio de los derechos o su suspensión extraordinaria. Este principio coincide con el rasgo fundamental del derecho de los derechos humanos, esto es, estar siempre a favor del hombre $(2013$, p. 1$)$.

En el mismo sentido es reconocido por la Corte Constitucional, Sent.,C-187, 2006, remitiéndose a los articulos 5 del PIDCP y 29 de la CIDH, precisando que dicho principio hermenéutico rige nuestro ordenamiento, toda vez que por vía de suscripción a dichos instrumentos, el modelo normativo interno se obliga para con la observancia del contenido de dicho principio. Por tanto, su acatamiento obedece al cumplimiento del principio del pacta suntservanda, para lo cual el principio pro homine ha de enmarcar la hermenéutica del derecho interno, a efectos de armonizarlo con las obligaciones contraídas por el Estado Colombiano. Incluso, en diversas opiniones consultivas, la Corte Interamericana de Derechos Humanos, ha hecho énfasis en la aplicación de la cláusula de favorabilidad en la interpretación de los derechos humanos, respecto de garantias y libertades de la persona humana, imponiendo como directriz hermenéutica la que resulte más favorable, no solo en comparación del derecho interno de los Estados Parte, sino de este respecto a los diferentes pactos que haya suscrito, e incluso entre éstos últimos, tal y como se señaló en la opinión consultiva OC-1/82 del 24 de septiembre de 1982, y la OC-5/85 del 13 de noviembre de 1985. Incluso el Comité de Derechos Humanos de la ONU [CDH], en punto del derecho a la libertad y seguridad personal (art. 9 PIDCP), aplicó con carácter extensivo el principio pro homine, a efectos de ampliar el marco de aplicación dedicho derecho cuando señaló:

"El articulo 9, que trata del derecho a la libertad y a la seguridad personales, ha sido interpretado con frecuencia de forma bastante estricta en los informes de los estados parte, que por lo tanto han aportado una información incompleta. El Comité señala que el párrafo 1 es aplicable a todas las formas de privación de la libertad, ya sea como consecuencia de un delito o de otras razones, como por ejemplo las enfermedades mentales, la vagancia, la toxicomanía, las finalidades docentes, el control de inmigración, etc" (Comité de Derechos Humanos. Pacto de Derechos Civiles y Políticos, Observación general $n^{\circ} 8$, relativa a la libertad y a la seguridad personal (articulo 9 del Pacto), adoptada durante el 16 período de sesiones, 1982 párr. 1.).

O, como concluye en disenso de la postura de la Corte Interamericana de Derechos Humanos frente a la exigibilidad per se del derecho de rectificación del articulo 14 de la CADH: 
En este aspecto, me parece que el criterio fundamental es el que impone la naturaleza misma de los derechos humanos, la cual obliga a interpretar extensivamente las normas que los consagran o amplían y restrictivamente las que los limitan o restringen. Ese criterio fundamental - principio pro homine del derecho de los derechos humanos -, conduce a la conclusión de que su exigibilidad inmediata e incondicional es la regla, y su condicionamiento la excepción, de manera que si, en los términos en que está definido por la Convención el derecho de rectificación o respuesta, podría ser aplicado aun a falta de las referidas "condiciones que establezca la ley", es un derecho exigible per se (OEA, CrIDH, serie A: Fallos y opiniones $n^{\circ} 7$. Opinión consultiva OC-7/86, 1986, párr. 36).

Corolario de lo anterior, es dable precisar que una hermenéutica desfavorable en punto de libertad, para enmarcarnos dentro de la temática propuesta, lleva a la conculcación de reglas inherentes al principio pro homine, como la de protección, general de no intromisión, de prohibición de regresión y de interpretación favorable, más aún cuando de interpretar un texto normativo de confusa redacción se trata, como es el caso del parágrafo del articulo 57 de la ley 1453 de 2011.

\subsection{SOBRE LA DIVISIÓN DE PODERES}

El estado Colombiano tiene un ordenamiento constitucional que establece una división de poderes conforme a la separación de las ramas del poder público que integran la ejecutiva, legislativa y judicial, del que se desprende un ejercicio del poder limitado.

De conformidad con el articulo 150-2 de la C.N. le corresponde al Congreso de la República "Expedir los códigos en todos los ramos de la legislación y reformar sus disposiciones" por tanto le corresponde definir la características, etapas, términos y formalidades que integran cada procedimiento judicial, sin embargo, en esta labor el legislador tiene ciertos límites, representados fundamentalmente en su obligación de atender los principios y fines del Estado y develar por la vigencia de los derechos fundamentales de los ciudadanos.

El principio de legalidad, en un sentido amplio, no solo se refiere a que la norma cumpla con las exigencias de ser clara, expresa y taxativa, como se vio ut supra, sino que la misma debe ser emanada por parte del organismo constitucionalmente competente para ello, que para el caso sería el órgano legislativo.

Teniendo en cuenta entonces que el nuestro es un Estado Social, Democrático y de Derecho, en el cual se encuentra establecida la separación de poderes como una de sus características esenciales, donde cada rama tiene sus funciones claramente diferenciadas, y dentro de las cuales es de resorte de la legislativa la expedición de leyes, con la limitación de que las mismas se acompasen a la Constitución y en lo que atañe a leyes procedimentales respete principios de proporcionalidad y razonabilidad, cuando las leyes expedidas por el legislador no cumplen estos requisitos, no se torna en una 
habilitante para que la Corte Constitucional usurpe dichas funciones constitucionalmente encomendadas al aparato legislativo y cree leyes que se acompasen en mayor medida -según su criterio- a estos principios.

La función de la Corte Constitucional sería entonces cuando una norma que en su origen respete el principio de legalidad, por ser expedida por el legislador, pero no sea clara, proporcional, razonable y acorde con los principios del Estado, declararla inexequible y no entrar a promulgar, vía jurisprudencia, una ley que no fue la que originalmente hizo tránsito en el Congreso.

En el salvamento parcial de voto presentada por el Magistrado Sigifredo Espinoza Pérez, contra la sentencia con radicación 36502 señaló que la interpretación de dicha norma propuesta por la Corte Suprema de Justicia (retomada después por la Corte Constitucional) "genera una indebida intromisión en el ámbito de configuración del legislador, desconoce el debido proceso y los principios de legalidad y favor rei" proponiendo entonces que se acuda a la excepción de inconstitucionalidad, ya que no importa cómo se interprete la norma sub judice, siempre conduce a resultados que afecten principios basilares.

\section{CONCLUSIONES}

En razón de la promulgación de la Ley 1453 del 24 de junio de 2011, particularmente del parágrafo del articulo 57, así como el consecuente pronunciamiento de exequibilidad contenido en la sentencia C-645 del 24 de agosto de 2012, se conculcaron una serie de principios que rigen no solo nuestra Constitución, sino el Derecho Internacional De Los Derechos Humanos, que por vía de bloque de constitucionalidad se han incorporado a nuestro ordenamiento jurídico, y con tales pronunciamientos no solo se soslayan tales principios, sino que se socava la estructura misma que define al Estado Colombiano como un estado social y democrático de derecho, donde uno de sus pilares fundantes se erige desde la división de poderes y sus respectivas funciones.

Resulta claro que a quien le compete elaborar el conjunto de reglas que estructuran la legislación interna es a la rama legislativa, por expreso mandato del canon 114 de la Constitución Nacional, enmarcada su función en los fines del Estado, respecto de los cuales la misma Carta Política se ha encargado de acotar una serie de principios y derechos que deben observarse para el desarrollo de su actividad, además de aquellos principios que se incorporan por vía de lo dispuesto en el articulo 93 de dicha normatividad. Es así como la función del Congreso de Colombia, tendiente al desarrollo legal de la Constitución, debe dar origen a unas reglas que en su taxatividad sean claras, precisas y concisas, para no conculcar el principio de legalidad por vía de la inseguridad jurídica, lo cual, de una simple lectura del mandato contenido en el parágrafo del articulo 57 de la Ley 1453 del 24 de junio del 2011, es dable concluir la falta de claridad y su abierta contradicción respecto de la ley estatutaria del procedimiento penal que estableció el sistema penal 
acusatorio, Ley 906 de 2004, en tanto que atenta contra los principios de igualdad (art. 4), de lealtad procesal (art. 12) de la actuación procesal (art. 10), y su consecuente eficacia en el ejercicio de la justicia, así como el de prelación de los tratados internacionales (art. 3). Lo anterior sin mencionar la agresión que se da frente al principio de proporcionalidad que rige de manera inmanente las actuaciones punitivas del poder estatal, ya que por el solo hecho de encontrarse en flagrancia, un eventual allanamiento a cargos conllevaría una menor consecuencia premial, que un allanamiento bajo otras circunstancias, a pesar de darse este último como consecuencia de un mayor desgaste de la labor investigativa y la actividad del Estado.

Aunado a las falencias legislativas, que se apartaron con la elaboración legal antes mencionada del marco dado por el Acto Legislativo 03 de 2002, que introdujo el sistema penal acusatorio, se tiene que la Corte Constitucional en su sentencia de exequibilidad, C-645 del 24 de agosto de 2012, se apartó de sus funciones, pues entró a suplantar al legislador y a, en una amplísima interpretación, llenar los vacíos que en su criterio se habían dejado de lado en la normatividad en estudio. Es evidente que con ello se conculcó el principio de división de las ramas del poder público, el cual es fundante del concepto de estado social y democrático de derecho. Pero además desconoció de plano principios del Derecho Internacional De Los Derechos Humanos, como es el caso del principio pro homine y de favor rei, pues en una extraña interpretación de la norma, consideró ajustado a la constitución una situación fáctico - legal que imponía una hermenéutica en contra de los intereses de los procesados incursos en situación especial de flagrancia, aceptando así pretermitir la aplicación de dichos axiomas

\section{REFERENCIAS BIBLIOGRÁFICAS}

Comité de Derechos Humanos (1982). “Observación general $n^{\circ} 8$, relativa a la libertad y a la seguridad personal, adoptada durante el 16 período de sesiones". En: Pacto de Derechos Civiles y Políticos.

Constitución Política de Colombia (1991).

OEA (1969), Convención Americana de Derechos Humanos, San José de Costa Rica.

ONU (1969), Convención de Viena sobre el derecho de los tratados, Viena - Austria.

Corte Constitucional, Sala Plena (2001), Sentencia SU-1300. Magistrado Ponente: Monroy Cabra, Marco Gerardo.

Corte Constitucional, Sala Plena (2005), Sentencia C-1195. Magistrado Ponente: Araujo Rentería, Jaime. 
Corte Constitucional, Sala Plena (2005), Sentencia C-591. Magistrado Ponente: Vargas Hernández, Clara Inés.

Corte Constitucional, Sala Cuarta de Revisión (2006), SentenciaT-091. Magistrado Ponente: Córdoba Tribiño, Jaime.

Corte Constitucional, Sala Plena (2006), Sentencia C-187. Magistrado Ponente: Vargas Hernández, Clara Inés.

Corte Constitucional, Sala Tercera de Revisión (2007), Sentencia T-686. Magistrado Ponente: Córdoba Tribiño, Jaime.

Corte Constitucional, Sala Séptima de Revisión (2007), Sentencia T- 356. Magistrado Ponente: Sierra Porto, Humberto Antonio.

Corte Constitucional, Sala Plena (2010), Sentencia C-828. Magistrado Ponente: Sierra Porto, Humberto Antonio.

Corte Constitucional, Sala Plena (2012), Sentencia C-645. Magistrado Ponente: Pinilla Pinilla, Nilson.

Corte Suprema de Justicia, Sala Penal (2011), Sentencia 36.502. Magistrado Ponente: Gómez Quintero, Alfredo.

Corte Suprema de Justicia, Sala de Casación Penal (2006), Sentencia 25.136. Magistrado Ponente: Socha Salamanca, Julio Enrique.

Gutiérrez, R. (2009). "El Principio Pro-Homine”, Revista del Instituto de Estudios Penales, $\mathrm{N}^{\circ}$ 1. p. 27, recuperado de http://www.ijeditores.com.ar/articulos. php?idarticulo $=47330 \&$ print $=2$

Hernández, D. (2002). Lecciones de Derecho Internacional Humanitario. 2a Edición, Bogotá: Ediciones Nueva Jurídica.

Jauchen, E. (2005). Derechos del imputado. Buenos Aires: Rubinzal - Culzoni Editores

Ley 1453 de 2011. Por medio de la cual se reforma el Código Penal, el Código de Procedimiento Penal, el Código de Infancia Adolescencia, las reglas sobre extinción de dominio se dictan otras disposiciones en materia de seguridad. Junio 24 de 2011. D.O. N48110.

Londoño, C. (2011). Bloque de Constitucionalidad. Reimpresión 1ạ Edición. Bogotá: Ediciones Nueva Jurídica. 
OEA, Corte Interamericana de Derecho Humanos, “Opinión consultiva OC-1/82 del 24 de septiembre de 1982, "Otros tratados" objeto de la función consultiva de la Corte", serie A: Fallos y opiniones $n^{\circ} 1$.

OEA, Corte Interamericana de Derechos Humanos, "Opinión consultiva OC-5/85 del 13 de noviembre de 1985. La colegiación obligatoria de periodistas (arts. 13 y 29 Convención Americana sobre derechos humanos) solicitada por el Gobierno de Costa Rica. Párrs. 51 y 52", serie A: Fallos y opiniones $n^{\circ} 5$.

OEA, Corte Interamericana de Derechos Humanos, “Opinión consultiva OC-7/86 del 29 de agosto de 1986, exigibilidad del derecho de rectificación o respuesta (arts.14.1, 1.1 y 2 Convención Americana sobre derechos humanos), solicitada por el Gobierno de Costa Rica, opinión separada del juez Rodolfo E. Piza Escalante, párr. 36", serie A: Fallos y opiniones $n^{\circ} 7$.

ONU (1966), Pacto Internacional de Derechos Civiles y Políticos.

Pinto, Mónica. "El principio pro homine" En: Criterios de hermenéutica y pautas para la regulacióndelosderechoshumanos.P.1.,recuperadode: http://www.google.com.co/ $r l$ ?sa $=t \& r c t=j \& q=\& e s r c=s \&$ frm $=1 \&$ source=web\& $\mathrm{cd}=1 \&$ sqi $=2 \& v e d=0 C C k Q F j A A \& u r l$ =http\%3A\%2F\%2Fwww.derechoshumanos.unlp.edu.ar\%2Fassets\%2Ffiles\%2Fd ocumentos\%2Fel-principio-pro-homine-criterios-de-hermeneutica-y-pautas- $p$ a $r$ a - I a - re gulacion-de-los-derechos-humanos.doc \& e i = _uGAUrTLB4_PkQe y04CIDg\&usg=docAFQjCNGcmo51vZnVKgmP3GWoJL9QjFRLIg

Sapag, M. (2008). "Principio de proporcionalidad y de razonabilidad como límite constitucional al poder del Estado: un estudio comparado". En: Dikaion. Bogotá: Universidad de la Sabana Dikaion, año 22, núm. 17 , pág. 158-198, diciembre 2008. 